\title{
Nutritional supplementation practices during pregnancy in Village Development Committees of Morang District, Nepal
}

\section{Sah RB ${ }^{1}$, Subedi $\mathrm{L}^{2}$, Shah $\mathrm{U}^{3}$, Jha $\mathrm{N}^{4}$, Pokharel $\mathrm{PK}^{5}$}

${ }^{1}$ Associate Professor, ${ }^{2}$ Senior Instructor, ${ }^{4}$ Professor \& Chief, ${ }^{5}$ Professor, School of Public Health and Community Medicine, BP Koirala Institute of Health Sciences, Dharan, Nepal, ${ }^{3} \mathrm{M}$.Sc. student, Dept. of Microbiology, Sunsari Technical College Pvt. Ltd., Dharan

\section{ABSTRACT \\ BACKGROUND}

Pregnancy is a critical period for both woman and baby from a nutritional perspective. Poor nutrition, during pregnancy is associated with adverse maternal and fetal outcomes. However, due to various factors, pregnant women do not increase the quality or quantity of diet during pregnancy.

\section{OBJECTIVE}

To find out the prevalence of nutritional supplementations taken during pregnancy and to find out the association between sociodemographic characteristics and nutritional supplementations taken during pregnancy.

\section{MATERIALS AND METHODS}

The cross-sectional study was conducted from 1st March to 14th March, 2014 among the residents of Rangeli VDC of Morang District in Eastern Nepal where 300 households were taken as subjects. Semistructured questionnaire was used and face to face interview was conducted. Chi-square test was applied to find out the association between sociodemographic characteristics and nutritional supplementations taken during pregnancy.

\section{RESULT}

The problem of not taking extra nutritional supplementations during pregnancy is common and has become a key public health concern. Lack of education of wife and husband led some of the respondents not taking more nutritional supplementations during pregnancy.

\section{CONCLUSION}

The problem of not taking extra nutritional supplementations during pregnancy is common and has become a key public health concern. Lack of education of wife and husband led some of the respondents not taking more nutritional supplementations during pregnancy.

\section{Keywords: Nutritional supplementations, Practices, Pregnancy \& Nepal}

Correspondence: RB Sah

Email: bilaksah@yahoo.com 


\section{INTRODUCTION}

Every year more than 20 million infants are born with low birth weight worldwide. ${ }^{1}$ About 3.6 million infants die during the neonatal period. ${ }^{2}$ Two thirds of these deaths occur in southern Asia and sub-Saharan Africa. More than one third of child deaths are thought attributed to maternal and child undernutrition. ${ }^{3}$ Micronutrient deficiencies result from inadequate intake of meat, fruits and vegetables, and infections. Multiple micronutrient supplementation in pregnant women can be a promising strategy in reducing adverse pregnancy outcomes through improved maternal nutritional and immune status. ${ }^{4,5}$

Several systematic reviews of trials examining the effects of multiple micronutrient supplementation in mother have been conducted ${ }^{6-9}$ but they have had their limitations. Some studies showed that micronutrient supplementation can increase perinatal mortality, no one of the articles have addressed this issue more details. ${ }^{6-}$ ${ }^{8,10}$ None has examined the potential sources of heterogeneity in the effect of supplementation on perinatal mortality.

Multiple rather than single deficiencies are found commonly in low socioeconomic population and studies that address and bring together the broader picture of multiple nutrient intakes or deficiencies are lacking. ${ }^{5}$ Therefore, this study was conducted to find out the prevalence of nutritional supplementations taken during pregnancy and to find out the association between sociodemographic characteristics and nutritional supplementations taken during pregnancy.

\section{METHODS}

The cross-sectional study was conducted from $1^{\text {st }}$ March to $14^{\text {th }}$ March, 2014 among the residents of Rangeli VDC of Morang District in Eastern Nepal. A study showed that $58.9 \%$ of women have taken more nutritional supplementations (Oyibo PG et al in Nigeria in 2011) $)^{11}$, more than that (78.9\%) of women (Sanjel $\mathrm{S}$ in Nepal in 2011), ${ }^{12}$ and highest in Dhankuta, Nepal $(82.4 \%)$ (Sah RB in Dhankuta, Nepal in 2013) $)^{13}$. We obtained a sample size of 300 at $95 \%$ CI taking $58.9 \%$ prevalence of nutritional supplementation in pregnant mothers. ${ }^{11}$ All the participants aged 15 to 45 years from the selected households were included in the study. There are 9 wards in Rangeli VDC. Among 9 wards, the ward number 1, 2, 3 and 4 was randomly selected by lottery method. The list of households of these 4 wards was prepared and equal number of households (75) from each ward was selected on the basis of simple random sampling.

Semistructured questionnaire was administered to the study subjects in the presence of investigator and face to face interview was conducted. A written permission was taken from concerned authority and an informed verbal consent was taken from the participants of the study. Those families that were available after three visits and willing to give verbal consent were included in the study.

The collected data was entered in MS Excel 2000. The analysis was done by using statistical software SPSS (Statistical Package for Social Science) 17.0 version. Chi-square test was applied to find out the association between sociodemographic characteristics and nutritional supplementations taken during pregnancy. The probability of occurrence by chance is significant if $\mathrm{P}<0.05$ with $95 \%$ Confidence Interval. 
Journal of College of Medical Sciences-Nepal, 2014, Vol-10, No-2

\section{RESULTS}

Table 1: Distribution of study population by nutritional supplementations taken during pregnancy

\begin{tabular}{|c|c|c|}
\hline Characteristics & Frequency & Percent \\
\hline \multicolumn{3}{|l|}{ Food taken during pregnancy } \\
\hline Same/ More & 154 & 51.3 \\
\hline Less & 146 & 48.7 \\
\hline \multicolumn{3}{|l|}{ Diet restriction during pregnancy } \\
\hline Yes & 145 & 48.3 \\
\hline No & 155 & 51.7 \\
\hline \multicolumn{3}{|l|}{ If diet restriction then what $(\mathrm{n}=145)$} \\
\hline Urad, kalo, mass dal & 25 & 17.2 \\
\hline Chilly and lemon & 57 & 39.3 \\
\hline Pumpkin, cauliflower, tomatoes & 26 & 18.0 \\
\hline Green spinach leaves & 29 & 20.0 \\
\hline Papaya & 8 & 5.5 \\
\hline \multicolumn{3}{|l|}{ Special food taken during pregnancy } \\
\hline Yes & 120 & 40.0 \\
\hline No & 180 & 60.0 \\
\hline \multicolumn{3}{|l|}{ If special food taken then what $(n=120)$} \\
\hline Juice of jwaano & 21 & 17.5 \\
\hline Coconut & 32 & 26.7 \\
\hline Sugar candy (Misri) & 41 & 28.3 \\
\hline Meat, fruits, milk & 41 & 11.7 \\
\hline Kaju, kismis & 9 & 15.8 \\
\hline \multicolumn{3}{|l|}{ Working hour during pregnancy } \\
\hline Same & 14 & 48.3 \\
\hline Decreased & 51 & 50.7 \\
\hline Increased & 23 & 1.0 \\
\hline \multicolumn{3}{|l|}{ Drug taken during pregnancy } \\
\hline Yes & 52 & 1.7 \\
\hline No & 95 & 98.3 \\
\hline Total & 300 & 100.00 \\
\hline
\end{tabular}

Table 1 shows that $50 \%$ of pregnant women have taken more nutritional supplementations during pregnancy. Almost $40 \%$ of women have taken special food and forty eight percent of women have restricted diet during pregnancy. Only five percent of women have taken drugs during pregnancy. 
Sah RB et al., Nutritional supplementation practices.

Table 2: Association between socio-demographic variables and nutritional supplementations taken during pregnancy

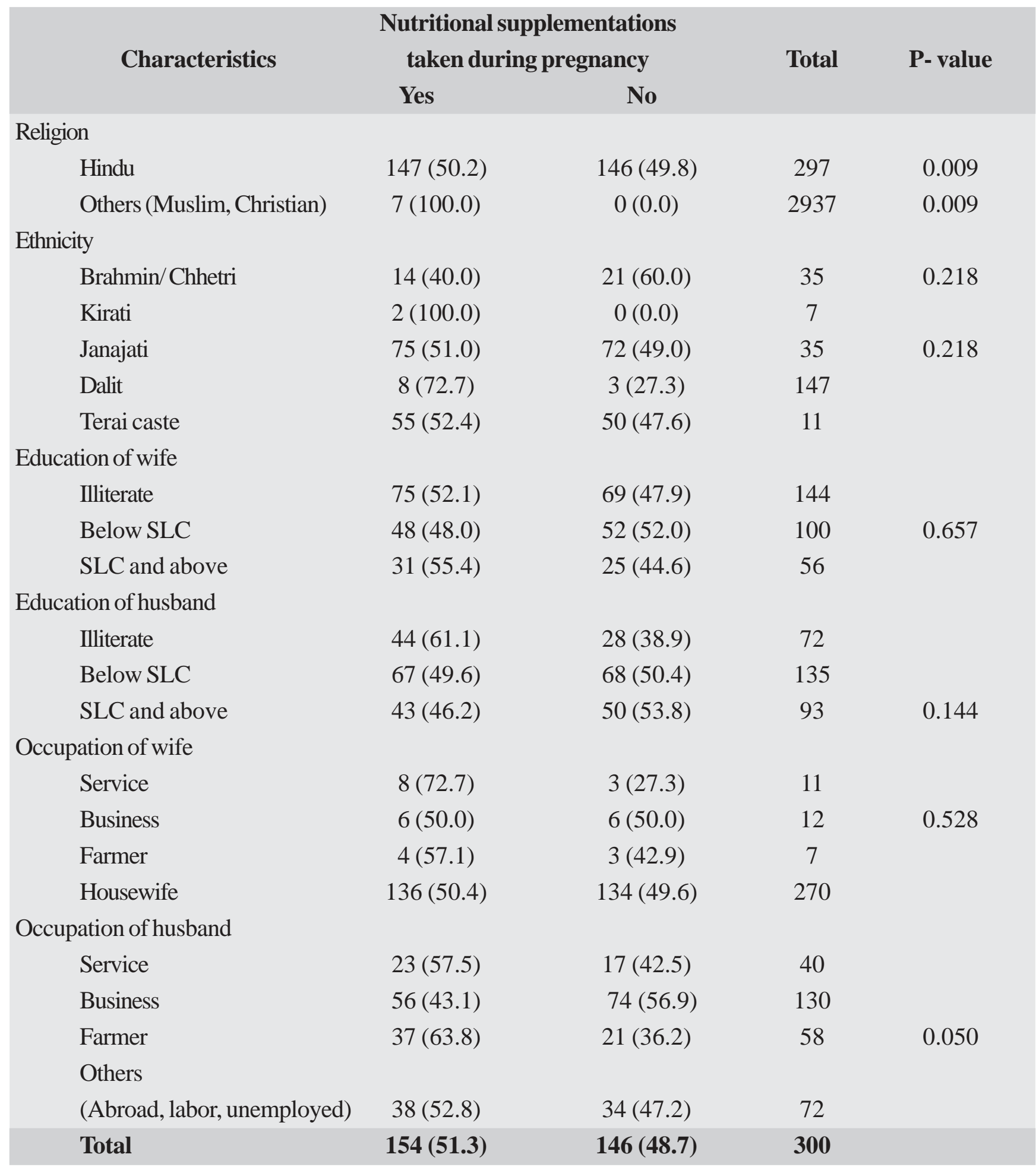

Table 2 shows that $40 \%$ of women of Brahmin/ Chhetri caste and almost $73 \%$ of women with Dalit ethnicity have taken more nutritional supplementations during pregnancy. The women with education level of SLC and higher have taken more nutritional supplementations than educational level below SLC and illiterate during pregnancy but the difference was not significant. Regarding occupation, the women with service have taken more nutritional supplementations than other occupational groups during pregnancy but the difference was not significant. 
Journal of College of Medical Sciences-Nepal, 2014, Vol-10, No-2

\section{DISCUSSION}

Several biological mechanisms can explain the beneficial effects of micronutrient supplementation on fetal growth. Women require more vitamins and minerals than normal during pregnancy and supplements can improve their nutritional status, haemoglobin status and functional immunity. ${ }^{14}$ Deficiencies of B-complex vitamins and folate are prevalent and may be a major cause of homocysteinaemia. ${ }^{3}$ Elevated homocysteine levels can lead to endothelial cell dysfunction and affect placental function. Thus, micronutrient supplements can help maintain normal homocysteine levels. Many vitamins and minerals also play important role in gene regulation and also in cellular metabolism and fetal growth. ${ }^{4}$

Current study showed almost $51.3 \%$ of pregnant women have taken more food during pregnancy. A study conducted by Abu-Saad K et al ${ }^{15}$ showed that adequacy of nutrients intake was low in pregnant women. Another study conducted by Hutter et $\mathrm{a}^{16}$ in rural south India also showed the practice of consuming fewer diet in pregnancy as compared to their non pregnant counterpart. This is because recommended dietary intake is more in pregnant women, but the study showed that dietary intake in pregnant women in rural resettlement colony is not very different from their non pregnant counterpart in terms of food group and nutrient intakes. The low calorie intake among both pregnant and non-pregnant women could be because of low socio-economic status as most of the subjects were from lower or middle socio-economic status.

This study showed almost $40 \%$ of pregnant women have taken special food (juice of jwaano, coconut, sugar candy (Misri), Meat, fruits, milk, Kaju and kismis) during pregnancy. More studies from Europe have presented data on maternal supplement use. In the DIPP study (Type 1 Diabetes Prediction and
Prevention Project) in 1998-2000, 85\% of the women reported taking special food during pregnancy which is higher than our study. ${ }^{17}$ In the All Babies in Southeast Sweden (ABIS) study in Sweden, $56 \%$ of the women took some type of dietary supplement during pregnancy in 1997-1999 ${ }^{18}$; this can be compared with, almost 10 years later, the $89 \%$ of Swedish women in TEDDY (The Environmental Determinants of Diabetes in the Young) who reported some type of dietary supplement. The high prevalence of supplement use in all TEDDY countries may be attributed to the recommendations on supplementation during pregnancy.

This study showed $48.3 \%$ of pregnant women have consumed less during pregnancy. In the study conducted by Negandhi $\mathrm{PH}$ et $\mathrm{al}^{19}$ showed that majority of pregnant participants are taking less than $80 \%$ of recommended nutrient intake, they are at a high risk of delivering low birth weight baby.This shows that a gap in knowledge about how much extra diet should be consumed in pregnancy is present.

This study did not show association between nutritional supplementations taken during pregnancy and ethnicity. But one of the few recent study on maternal supplement use and sociodemographic factors from the USA reports that nutritional supplementation is associated with ethnicity. ${ }^{20}$ We did not observe differences regarding ethnicity when looking for any supplement use of diet in pregnancy. This may be due to the inadequate definition of supplement use. The description of any dietary supplement use is very broad as it may contain supplement use for health-seeking reasons (enhance the diet) and/or for medical reasons (e.g. anaemia). We do not have information about the reason why women use dietary supplements and are therefore not able to separate these behaviours. However, when looking at vitamin D containing 
Sah RB et al., Nutritional supplementation practices.

supplements, women with ethnicity other than nonHispanic white were less likely in USA. ${ }^{20}$

Our study showed the women with education level of SLC and higher education have taken more nutritional supplementations than women with education level below SLC and illiterates during pregnancy but the difference was not significant. The women with education level below SLC and illiterates may be correlated with the limited access to health facilities and taking less nutritional supplementations during pregnancy. ${ }^{21}$ Mothers with limited education are less likely to take more nutritional supplementations, to seek neonatal care and more likely to be at risk of adverse pregnancy outcomes. ${ }^{21}$ Picciano and McGuire 22 reviewed diet supplement use in the United States and found a paucity of data concerning the use of dietary supplements during pregnancy. Although use of dietary supplements in the general US population is high and growing, demographic, sociologic, and economic factors influence supplement use. Female supplement users tended to be non-Hispanic white, more educated, and more affluent. ${ }^{23}$ The variable maternal education only affected women in the USA and Sweden. It has been implied that a higher education level gives a greater awareness of the role of nutrition in good health. 24,25

Few studies have examined the effects of micronutrient supplementation on long-term child health outcomes, such as child mortality, morbidity, growth and cognitive development. A large trial in Indonesia showed that prenatal micronutrient supplementation was associated with a significant $18 \%$ reduction in early infant mortality. ${ }^{26}$ Among Bhutanese refugees dependent on food aid, the incidence of low birth weight declined from $16 \%$ to $8 \%$ after 2 to 3 years of implementation of micronutrient-fortified foods. ${ }^{27}$
The limitation of this study was that the study was not longitudinal and thus it was not able to detect the difference in dietary intake in pregnant and non pregnant state in the same person.

\section{CONCLUSION}

We conclude that the problem of taking inadequate nutritional supplementations during pregnancy is common and has become a key public health concern. The pregnant women living in rural areas do not increase their dietary intake in pregnancy. Lack of education of wife and husband led some of the respondents not taken nutritional supplementations during pregnancy. Thus, there is a need to educate women regarding amount of food that should be consumed in pregnancy. Health education can be provided through mass media regarding how to increase dietary intake in pregnancy. Also health personnel should practice providing diet plan comprising of locally available and affordable food items to pregnant women during routine antenatal checkups.

\section{ACKNOWLEDGEMENT}

We would like to thank School of Public Health and Community Medicine for approval of our research work. We would like to acknowledge the $6^{\text {th }}$ semester students of MBBS Batch 2011 who helped us during the study period and participants of Rangeli VDC.

\section{REFERENCES}

1. Low birth weight: country, regional and global estimates. New York: United Nations Children's Fund \& World Health Organization; 2004. 
2. Black RE, Cousens S, Johnson HL, et al. Child Health Epidemiology Reference Group of WHO and UNICEF. Global, regional, and national causes of child mortality in 2008: a systematic analysis. Lancet 2010; 375: 1969-87.

3. Black RE, Allen LH, Bhutta ZA, et al. Maternal and child undernutrition: global and regional exposures and health consequences. Lancet 2008; 371:243-60.

4. Allen LH. Multiple micronutrients in pregnancy and lactation: an overview. Am J Clin Nutr 2005; 81: 1206-12.

5. Bhutta ZA, Ahmed T, Black RE, et al. Interventions for maternal and child undernutrition and survival. Lancet 2008; 371:417-40.

6. Haider BA, Bhutta ZA. Multiple-micronutrient supplementation for women during pregnancy. Cochrane Database Syst Rev 2006; 4: 4-18.

7. Shah PS, Ohlsson A. Knowledge synthesis group on determinants of Low birth weight and preterm births. Effects of prenatal MMN supplementation on pregnancy outcomes: a meta-analysis. CMAJ 2009; 180:99-108.

8. Ronsmans C, Fisher DJ, Osmond C, et al. Multiple micronutrient supplementation during pregnancy in low-income countries: a meta-analysis of effects on stillbirths and on early and late neonatal mortality. Food Nutr Bull 2009; 30:547-57.

9. Fall $\mathrm{CH}$, Fisher DJ, Osmond C, et al. Multiple micronutrient supplementation during pregnancy in low-income countries: a meta-analysis of effects on birth size and length of gestation. Food Nutr Bull 2009; 30:533-46.
10. Christian P, Osrin D, Manandhar DS, et al. Antenatal micronutrient supplements in Nepal. Lancet 2005; 366:711-12.

11. Oyibo PG, Ebeigbe PN, Nwonwu EU. Assessment of the risk status of pregnant women presenting for antenatal care in a rural health facility in Ebonyi State, South Eastern Nigeria. N Am J Med Sci 2011; 3 (9):424-27.

12. Sanjel S, Ghimire RH, Pun K. Antenatal care practices in Tamang community of hilly area in central Nepal. Kathmandu Univ Med J 2011; 34 (2): 57-61.

13. Sah RB, Gaurav K, Baral DD, et al. Antenatal care practices in hilly area of Eastern region of Nepal. Journal of Chitwan Medical College 2013; 3 (4): $12-5$.

14. Wintergerst ES, Maggini S, Hornig DH. Contribution of selected vitamins and trace elements to immune function. Ann Nutr Metab 2007; 51: 301-23.

15. Abu-Saad K, Fraser D. Maternal nutrition and birth outcomes. Epidemiol Rev 2010; 32:5.

16. Hutter I. Reduction of food intake during pregnancy in rural south India. Trop Med Int Health 1996; 1:399-405.

17. Arkkola T, Uusitalo U, Pietika"MI. Dietary intake and use of dietary supplements in relation to demographic variables among pregnant Finnish women. Br J Nutr 2006; 96: 913-20.

18. Brekke HK, Ludvigsson J. Vitamin D supplementation and diabetes related autoimmunity in the ABIS study. Pediatr Diabetes 2007; 8: 11-4.

19. Negandhi PH, Negandhi HN, Zodpey SP, et al. Risk factors for low birth weight in an Indian urban setting: A nested case control study. Asia Pac J 
Sah RB et al., Nutritional supplementation practices.

Public Health 2011, doi: 10.1177/1010539511431486.

Available from: http:// aph. sagepub.com/content/ early/2011/12/08/101053951141486 (Accessed on 2014 June 2)

20. Cogswell ME, Khan LK, Ramakrishnan U. Iron supplement use among women in the United States: science, policy and practice. J Nutr 2003; 133 (6): 1974-77.

21. Wagstaff A, Bustreo F, Bryce J, Claeson M. WHOWorld Bank Child Health and Poverty Working Group. Child health: reaching the poor. Am J Public Health 2004; 94: 726-36.

22. Picciano MF, McGuire MK. Use of dietary supplements by pregnant and lactating women in North America. Am J Clin Nutr 2009; 89: 663-7.

23. Yu SM, Kogan MD, Huang ZJ. Vitamin-mineral supplement use among US women. J Am Med Womens Assoc 2003; 58:157-64.
24. Foote JA, Murphy SP, Wilkens L. Factors associated with dietary supplement use among healthy adults of five ethnicities. The Multiethnic Cohort Study. Am J Epidemiol 2003; 157, 888-97.

25. Conner M, Kirk S, Cade J. Environmental influences: factors influencing a woman's decision to use dietary supplements. J Nutr 2003; 133 (6): 1978-82.

26. Shankar AH, Jahari AB, Sebayang SK, et al. Effect of maternal multiple micronutrient supplementation on fetal loss and infant death in Indonesia: a doubleblind cluster-randomised trial. Lancet 2008; 371 : 215-27.

27. Shrimpton R, Thorne-Lyman A, Tripp K, et al. Trends in low birth weight among the Bhutanese refugee population in Nepal. Food Nutr Bull 2009; 30: 197-206. 